\title{
Tyrosylprotein sulfotransferase 1 expression is negatively correlated with c-Met and lymph node metastasis in human lung cancer
}

\author{
ZHIBIN JIANG ${ }^{1}$, JIALIANG ZHU ${ }^{1}$, YUCHAO MA ${ }^{1}, \mathrm{CAO} \mathrm{HONG}^{1}$, SHENG XIAO $^{2}$ and LONGYU JIN ${ }^{1}$ \\ Departments of ${ }^{1}$ Cardiothoracic Surgery and ${ }^{2}$ Pathology, The Third Xiangya Hospital, \\ Central South University, Changsha, Hunan 410013, P.R. China
}

Received October 6, 2014; Accepted June 23, 2015

DOI: $10.3892 / \mathrm{mmr} .2015 .4096$

\begin{abstract}
The present study aimed to test the expression of tyrosylprotein sulfotransferase 1 (TPST-1) in human lung cancer and to analyze the correlation with clinicopathologic features and c-Met expression levels. Expression levels of TPST-1 and c-Met were analyzed by immunohistochemistry in 50 lung cancer tissues. Non-neoplastic tissues $5 \mathrm{~cm}$ from the cancer tissues were collected as controls. The association between TPST-1 and c-Met expression and TPST-1 and clinicopathologic parameters was then analyzed. TPST-1 was expressed in all normal tissue samples, but only in $60 \%$ of lung cancer tissues. In tumor tissues, they appeared to be significantly lower than those in matched control lung tissues. The expression of TPST-1 was significantly correlated with the tumor-node-metastasis (TNM) stage and lymph node metastasis and was significantly inversely associated with c-Met expression. In conclusion, the present study demonstrated that TPST-1 expression was associated with the TNM stage and lymph node metastasis in patients with lung cancer. TPST-1 was significantly negatively correlated with the expression of c-Met in lung cancer and may be a negative prognostic biomarker of lung cancer.
\end{abstract}

\section{Introduction}

Lung cancer has been and remains the most common malignancy in the world, with an estimated 1.6 million novel cases per year (1). Despite the great progress made in several areas of oncology, the treatment and outcome of lung cancer have not significantly improved $(2,3)$. Its high mortality rate is attributed to a high incidence of metastases, thereby making systemic

Correspondence to: Professor Longyu Jin, Department of Cardiothoracic Surgery, The Third Xiangya Hospital, Central South University, 138 Tongzipo Road, Changsha, Hunan 410013, P.R. China E-mail: jinlongyu1123@163.com

Abbreviations: TPST, tyrosylprotein sulfotransferase

Key words: tyrosylprotein sulfotransferase 1, lung cancer, c-Met therapies the mainstay for treatment. As chemotherapy against metastatic lung cancer has yet to be shown effective $(4,5)$, molecular targets are required to be established to design appropriate pharmacologic agents to provide novel treatment modalities. In recent years, targeted therapies, including those directed towards epidermal growth factor receptor, anaplastic lymphoma kinase, mesenchymal-epithelial transition factor and angiogenesis, have been increasingly used (6-9). However, other pathways or molecular biomarkers may be identified in lung cancer.

Tyrosylprotein sulfotransferase (TPST) is a 54-to $50-\mathrm{kDa}$ integral membrane glycoprotein of the trans-Golgi network found in essentially all tissues investigated, catalyzing the tyrosine $\mathrm{O}$-sulfation of soluble and membrane proteins passing through this compartment (10). Two different TPSTs (TPST-1 and TPST-2) have been identified $(11,12)$ and are broadly co-expressed in human tissues $(13,14)$. The levels of TPST-1 and TPST-2 expression vary among different tissues, which may imply distinct physiological functions of TPST-1 and TPST-2 (14). Several studies have found that TPST-1 is highly expressed in breast cacinoma (15), oral squamous cell carcinoma (16) and soft-tissue sarcoma (17) compared with expression levels in normal tissues. In addition, a recent study of human nasopharyngeal carcinoma (NPC) found that the expression of TPST-1 was directly and clinically correlated with NPC and was associated with metastasis (18).

To the best of our knowledge, little has been uncovered regarding the involvement of TPST genes in lung cancer. TPST expression may be associated with treatment efficacy or prognosis in patients with lung cancer; however, the knowledge concerning TPST expression in lung cancer is currently insufficient. Overexpression of c-Met has been described in lung cancer and a multitude of other malignant human neoplasms (19-21). The present study was designed to clarify the TPST-1 expression in lung cancer by using a number of consecutive cases of primary tumors with complete histopathologic and clinical data.

\section{Materials and methods}

Patients and tumors. The present study was approved by The Third Xiangya Hospital Institutional Review Board of 
Central South University (Changsha, China). All patients with stage I-IV lung cancer who were undergoing a tumor resection or biospy procedure at the Third Xiangya Hospital between March 2010 and October 2012 were included. None of the patients received pre-operative chemotherapy, and all were treated with routine chemotherapy after the operation. Fixed in formaldehyde and embedded in paraffin, the specimens from 50 patients ( 16 women, 34 men) who were pathologically diagnosed with lung cancer were available for the present study. Clinical data of patients were obtained through a retrospective analysis of the reports. Clinical staging was based on the 7th edition of the tumor-node-metastasis (TNM) classification for lung cancer (22). In addition, surgically removed non-neoplastic tissues $5 \mathrm{~cm}$ from the cancer tissues were used as controls. Written informed consent was obtained from all the participants involved in the present study.

Antibodies. A rabbit polyclonal antibody against human TPST-1 (cat no. SAB1300286) and a mouse monoclonal antibody against human c-Met (cat. no. SAB4501869) were obtained from Sigma-Aldrich (St. Louis, MO, USA).

Immunohistochemistry. Immunohistochemistry staining was performed using the two-step EnVision ${ }^{\mathrm{TM}}$ method (Dako, Glostrup, Denmark). Briefly, 5- $\mu \mathrm{m}$ tissue sections were cut from each of the selected 50 paraffin-embedded tumor and control specimens, and they were dried at $65^{\circ} \mathrm{C}$ for $30 \mathrm{~min}$. The sections were de-paraffinized with xylene and re-hydrated with a graded ethanol series. Endogenous peroxide blocking was performed with 3\% hydrogen peroxide (Sinopharm Chemical Reagent Co. Ltd., Shanghai, China) for $10 \mathrm{~min}$, and antigen retrieval was performed at $100^{\circ} \mathrm{C}$ for $30 \mathrm{~min}$ in a citrate buffer (10 mmol/l; pH 6.0; Beijing Zhongshan Golden Bridge Biotechnology Co., Ltd., Beijing, China). After the sections were washed three times with phosphate-buffered saline (PBS; Sigma-Aldrich) for $3 \mathrm{~min}$ each, they were incubated with $10 \%$ normal goat serum (Beijing Zhongshan Golden Bridge Biotechnology Co., Ltd.) to block the non-specific binding. Then, the sections were incubated with the anti-human TPST-1 (1:150 dilution), and c-Met (1:500 dilution) monoclonal antibodies at $4^{\circ} \mathrm{C}$ overnight. After the sections were washed with PBS, the secondary antibody, peroxidase-conjugated goat anti-rabbit/mouse immunoglobulin G (no. K5007; Bottle A; Dako REAL ${ }^{\mathrm{TM}}$ EnVision $^{\mathrm{TM}}$; Dako, Glostrup, Denmark) was applied for $15 \mathrm{~min}$. The peroxidase reaction was developed for $3 \mathrm{~min}$ at room temperature with 3,3'-diaminobenzidine tetrahydrochloride (Sigma-Aldrich) with $0.03 \%$ hydrogen peroxide. Counterstaining was performed with Mayer's hematoxylin. The negative control was prepared with omission of the primary antibody and the use of normal serum instead of the primary antibody.

Evaluation of immunostaining. Two independent pathologists who were blinded to the clinical data evaluated the staining results. Any cases where inter-observer discrepancy occurred were reviewed at the double-head microscope (Olympus, Tokyo, Japan), and an agreement was reached. Immunochemical scoring was evaluated in a semi-quantitative fashion according to the similar method described by Jiang et al (23). It was based on the percentage of positive cells and the intensity of
Table I. Demographic characteristics of the lung cancer patients.

\begin{tabular}{lcc}
\hline Parameter & Patients (n) & $\%$ \\
\hline Mean age (years) & 50 & $59.84 \pm 9.59$ \\
Gender & 16 & 32 \\
Female & 34 & 68 \\
Male & & \\
Histological type & 20 & 40 \\
Squamous & 25 & 50 \\
Adeno & 5 & 10 \\
Other & & \\
Differentiation & 10 & 20 \\
Well & 27 & 54 \\
Moderate & 13 & 26 \\
Poor or undifferentiated & & \\
TNM stage & 9 & 18 \\
I & 11 & 22 \\
II & 23 & 46 \\
III & 7 & 14 \\
IV & & \\
Lymph node metastasis & 27 & 54 \\
Yes & 23 & 46 \\
No & & \\
Surgery & 43 & 86 \\
Lobectomy/pneumonectomy & 7 & 14 \\
Biospy & & \\
\end{tabular}

TNM, tumor-node-metastasis.

Table II. Expression of tyrosylprotein sulfotransferase in the tumor group and in the control group.

\begin{tabular}{lcc}
\hline Group & Positive, $\mathrm{n}(\%)$ & Negative, $\mathrm{n}(\%)$ \\
\hline Tumor & $30(60.0)$ & $20(40.0)$ \\
Control & $50(100.0)$ & $0(0.0)$ \\
\hline
\end{tabular}

$\mathrm{P}=0.001$, tumor vs. control group.

staining in their cytoplasm in five randomly visual fields under the optical microscope. The intensity of staining was scored as follows: 0 , without stain; 1 , straw yellow; 2 , brown; and 3, dark brown. According to the percentage of tumor cells stained positive, the extent of staining was scored as follows: $0, \leq 5 \%$; $1,6-25 \% ; 2,26-50 \% ; 3,51-75 \%$; and $4,>75 \%$. The product of the intensity and extent of staining yielded final scores: $\leq 1$, negative; $2-3$, weakly positive (1+); $4-5$, moderately positive $(2+)$; and $\geq 6$, strongly positive (3+).

Statistical analyses. The data were processed and statistically analyzed using SPSS for Windows XP (Version 13.0; SPSS, Inc., Chicago, IL, USA). The significance of the association 
Table III. Association between TPST-1 expression and clinicopathologic variables.

TPST-1 expression

\begin{tabular}{lccc} 
Variable & Patients, $(\%)$ & Positive, $(\%)$ & Negative, n $(\%)$ \\
\hline Histological type & & & $7(35.0)$ \\
$\quad$ Squamous & $20(40)$ & $13(65.0)$ & $11(44.0)$ \\
Adeno & $25(50)$ & $14(56.0)$ & $2(40.0)$ \\
Other & $5(10)$ & $3(60.0)$ & $4(40.0)$ \\
Differentiation & & $6(60.0)$ & $10(37.0)$ \\
Well & $10(20)$ & $17(63.0)$ & $6(46.2)$ \\
Moderate & $27(54)$ & $7(53.8)$ & $2(22.2)$ \\
Poor or undifferentiated & $13(26)$ & $7(77.8)$ & $2(18.2)$ \\
TNM stage & $9(18)$ & $9(81.8)$ & $9(39.1)$ \\
I & $11(22)$ & $14(60.9)$ & $7(100)$ \\
II & $23(46)$ & $0(0)$ & 0.925 \\
III & $7(14)$ & $10(37.0)$ & $17(63.0)$ \\
IV & & $20(87.0)$ & $3(13.0)$ \\
Lymph node metastasis & $27(54)$ & & 0.002 \\
Yes & $23(46)$ & & $<0.001$ \\
No & & &
\end{tabular}

TPST, tyrosylprotein sulfotransferase; TNM, tumor-node-metastasis.

Table IV. Association of TPST-1 expression with c-Met expression in patients with lung cancer [n (\%)].

\begin{tabular}{lccccc}
\hline & \multicolumn{3}{c}{ TPST-1 expression } \\
\cline { 3 - 5 } c-Met expression & Negative & Positive (1+) & Positive (2+) & Positive (3+) & $\mathrm{r}$ \\
\hline Negative & $2(16.7)$ & $1(8.3)$ & $2(16.7)$ & $7(58.3)$ & -0.470 \\
Positive (1+) & $5(41.7)$ & $1(8.3)$ & $2(16.7)$ & $4(33.3)$ & 0.001 \\
Positive (2+) & $5(45.5)$ & $3(27.3)$ & $2(18.2)$ & $1(9.1)$ & $0(0.0)$ \\
Positive (3+) & $8(53.3)$ & $6(40.0)$ & $1(6.7)$ & & \\
\hline
\end{tabular}

TPST, tyrosylprotein sulfotransferase.

between immunohistochemical expression and clinical variables was evaluated by using the $\chi^{2}$ test or Fisher's exact test, as appropriate. Spearman's rank correlation analysis was used to analyze the association between TPST-1, and c-Met expression levels. $\mathrm{P}<0.05$ was considered to indicate a statistically significant difference.

\section{Results}

Patients' demographic data. A total of 50 patients (16 women, 34 men) with stage I-IV lung cancerwere enrolled in the present study. The mean age of the patients was $59.84 \pm 9.59$ years (mean \pm standard deviation; range, 18-77 years). Among the 50 patients with lung cancer, $9(18 \%)$ were stage I, 11 (22\%) were stage II, $23(46 \%)$ were stage III and $7(14 \%)$ were stage IV. All patient characteristics are summarized in Table I.
Expression of TPST-1 is decreased in lung cancer tissues. Positive expression of TPST-1 was identified as a brownish yellow stain in the cytoplasm of lung cancer cells (Fig. 1). Immunohistochemical analysis demonstrated that TPST-1 was expressed in all matched control lung tissues (100\%) and in 30 out of $50(60 \%)$ tumor tissues. The expression of TPST-1 in tumor tissues appeared to be significantly lower than that in matched control lung tissues $(\mathrm{P}=0.001)$. Table II shows the results of the expression of TPST-1 in the tumor group and the control group.

TPST-1 expression is associated with clinical tumor stage, TNM stage and lymph node metastasis. The association of clinicopathologic characteristics with TPST-1 expression in lung cancer tissues is summarized in Table III. The expression of TPST-1 in clinical stage IV cases was lower than that in clinical stage I-II cases (Fig. 2). In addition, TPST-1 expression 

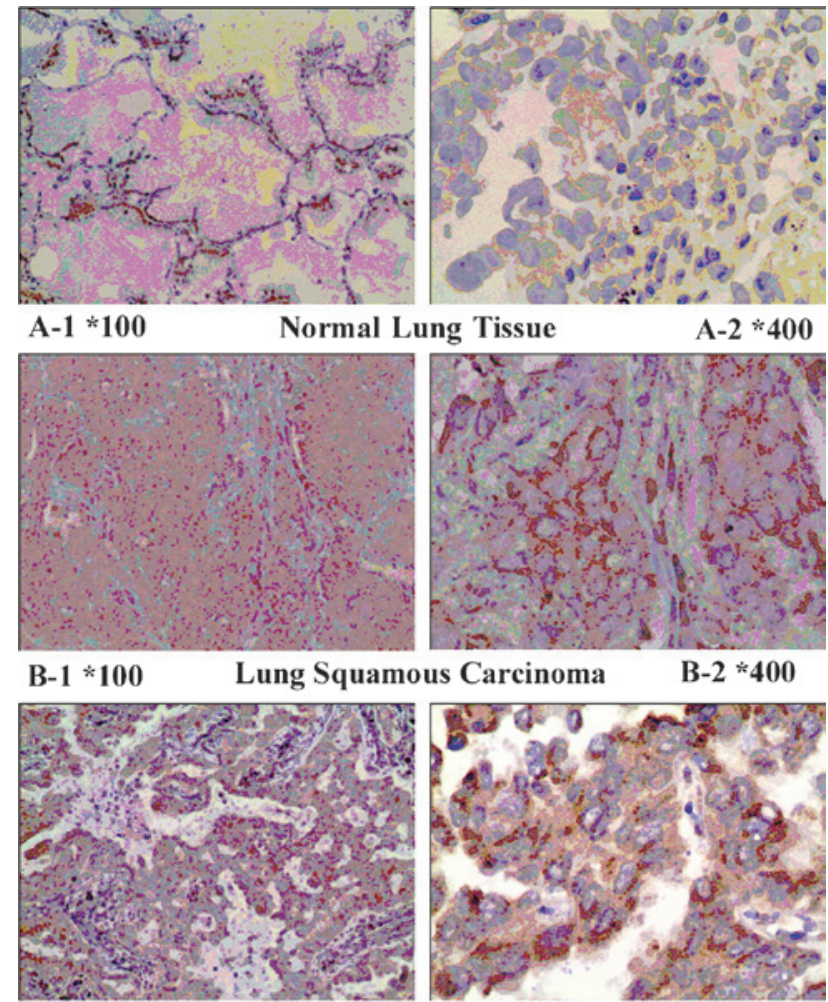

B-2 2400
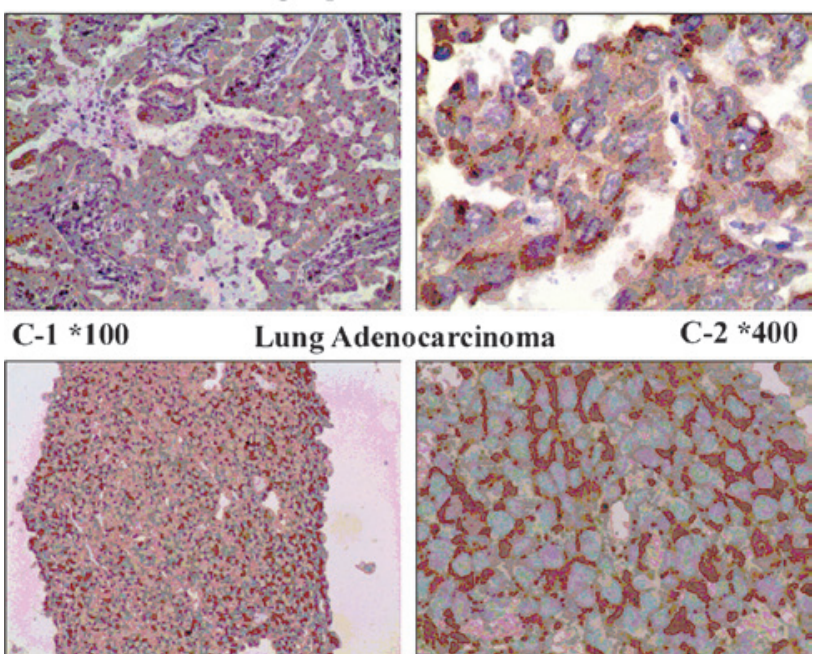

C- $2 * 400$

D-1 $* 100$
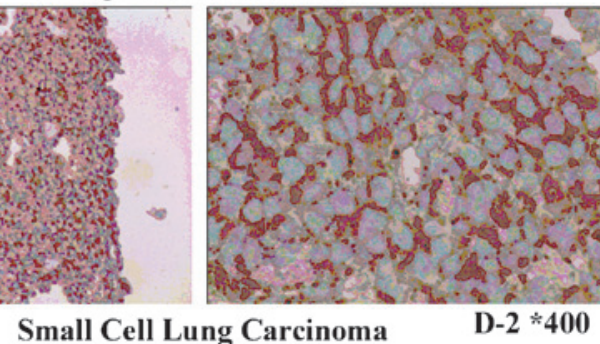

Figure 1. Immunohistochemical analysis of tyrosylprotein sulfotransferase in (A) normal lung tissue, (B) lung squamous carcinoma, (C) lung adenocarcinoma and (D) small cell lung carcinoma (magnification, $\mathrm{x} 100$ and $\mathrm{x} 400$ in the left- and right-hand images, respectively. Positive expression is indicated by a brown stain.
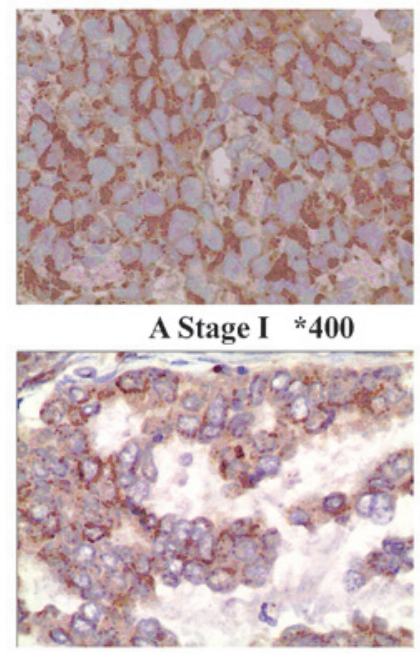

C Stage III $* 400$

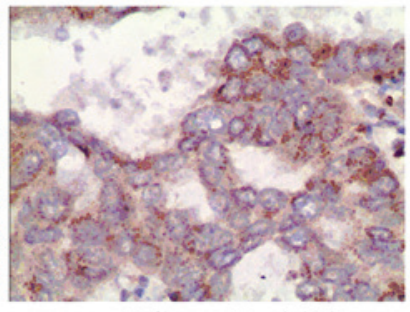

B Stage II $* 400$

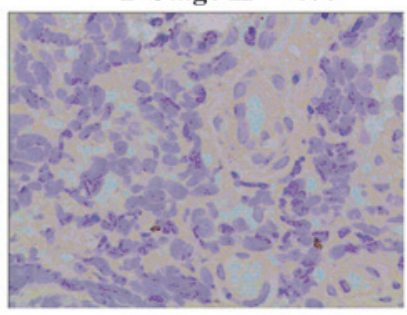

D Stage IV *400
Figure 2. Expression of tyrosylprotein sulfotransferase in different clinical stages: (A) Stage I (B) Stage II (C) Stage III and (D) Stage IV (magnification, $\mathrm{x} 400$ ). Expression in stage IV cases was lower than in clinical stage I-II cases.

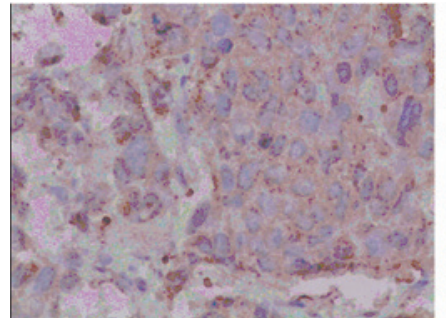

lymph node metastasis $* 400$

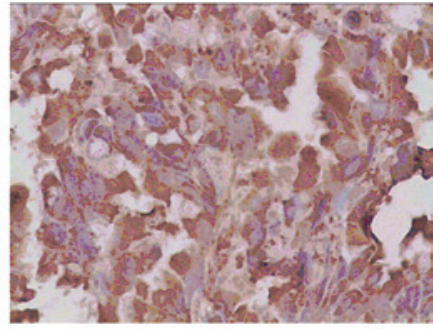

no lymph node metastasis $* 400$
Figure 3. The expression of TPST-1 in tumor samples from lung cancer patients without lymph node metastasis (right) was higher than that in patients with lymph node metastasis (left). The expression of TPST-1 was significantly associated with lymph node metastasis in lung cancer tissue. TPST-1, tyrosylprotein sulfotransferase.

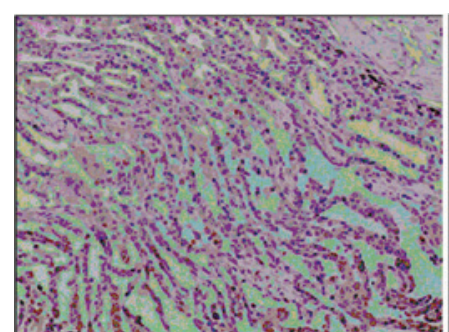

C-Met +

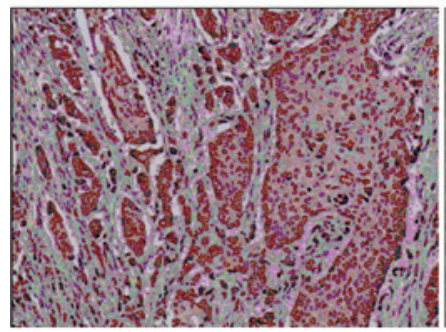

C-Met ++

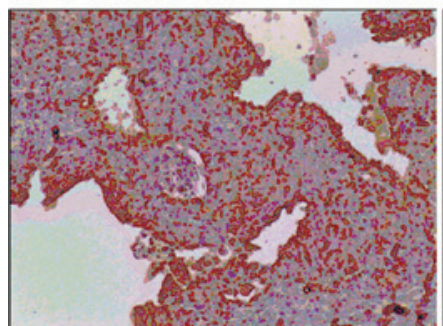

C-Met +++

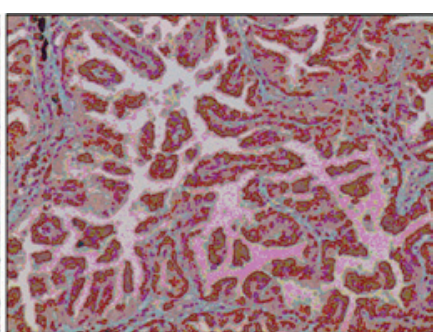

TPST-1 ++

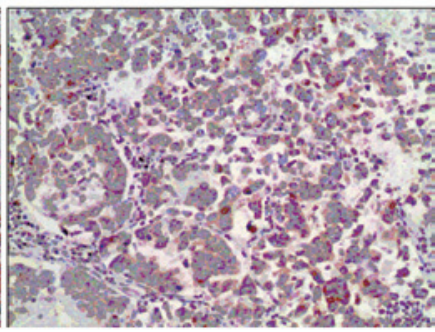

TPST-1 ++

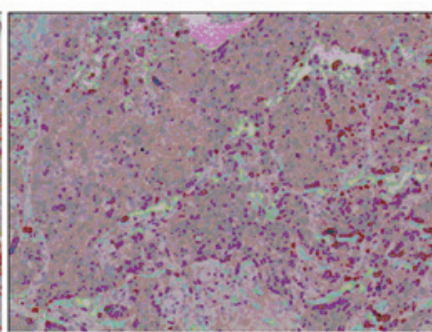

TPST-1 +
Figure 4. Immunohistochemical detection of the expression of TPST-1 and c-Met in tumor tissues. A negative association was observed between TPST-1 expression and c-Met expression in tumor tissues. TPST-1, tyrosylprotein sulfotransferase.

was highly associated with the TNM stage $(\mathrm{P}=0.002)$ and lymph node metastasis $(\mathrm{P}<0.001)$ (Fig. 3). However, statistical analysis revealed no significant correlations between the expression of TPST-1 and the histological type or tumor differentiation.

TPST-1 expression is inversely correlated with c-Met expression in lung cancer tissues. The present study further investigated the association between TPST-1 and c-Met expression in tumor tissues by immunohistochemical scoring. A significant association between TPST-1 and c-Met expression 
levels was identified ( $\mathrm{r}=-0.470, \mathrm{P}=0.001)$ (Fig. 4). Table IV shows the negative association between TPST-1 expression and c-Met expression in tumor tissues.

\section{Discussion}

Individual patients with lung cancer respond differently to chemotherapy and have different survival rates. This variability is associated with the histological lung cancer sub-type and its individual biological characteristics (24). Therefore, it is important to enhance the current knowledge of the pathophysiology and molecular profiles of the different histological types of lung cancer, thus allowing for personalization of the available therapies.

TPST is an enzyme responsible for protein tyrosine sulfation (25), which enhances protein-protein interactions, thereby having an important functional role. The present study hypothesized that a change in tyrosine sulfation of human trypsinogens may alter the risk for numerous types of disease. This notion was based on the observation that human trypsinogens undergo post-translational sulfation modification in peptides and proteins synthesized through the secretory pathway of most eukaryotes (13). In fact, several studies have proved that TPST-1 deficiency results in a series of dysfunction. Among these studies, Westmuckett et al (26) found that TPST deficiency results in early post-natal pulmonary failure in mice. Another study found that a loss-of-function mutant of the Arabidopsis TPST displayed a markedly abnormal phenotype including severely stunted growth and early senescence (27). In addition, double knockout of TPST-1 and TPST-2 was found to severely disrupt the integrity of the retina, resulting in abnormal disc morphology (28). In summary, the previous studies demonstrated that protein-tyrosine sulfation is a key determinant in the development and maintenance of tissue function.

To the best of our knowledge, there have been no previous studies regarding TPST-1 expression in lung cancer tissue and their possible roles in conjunction with the clinical outcome of lung cancer patients by means of any modalities. The present study identified TPST-1 expression in all normal control lung tissues. These data confirmed once again that TPST-1 is expressed in normal tissues, in line with a study by Mishiro et al (14). However, the present study also observed that TPST-1 was expressed in only 30 out of $50(60 \%)$ tumor tissue samples. It has not yet been determined why TPST-1 expression is reduced in lung cancer. It is possible that tumors may be caused by insufficient protein-tyrosine sulfation. Of note, a recently published study on NPC showed that TPST-1 was up-regulated at the mRNA as well as the protein level in NPC cells, and this up-regulation was associated with metastasis (18). This result is contrary to the observation of the present study. This phenomenon may be explained by the fact that different tumor types have different signal transduction pathways and different mechanisms. Another possible explanation is that the authors of the aforementioned study was performed using NPC cells cultured in vitro, whereas the present study assessed tumor samples from patients.

The present study observed a tendency toward a lower expression rate of TPST-1 when the lung cancer TNM stage was advanced. Furthermore, TPST-1 expression in patients with lymph node metastasis was significantly lower than that in patients without lymph node metastasis. All these results demonstrated that TPST-1 may be a useful prognostic biomarker. Detection of TPST-1 expression in tumor tissue may provide a more exact prognosis for patients with lung cancer.

C-Met, a high-affinity receptor for hepatocyte growth factor, is usually considered as an oncogene (29). Abnormalities regarding C-Met, including protein overexpression, gene mutation and gene amplification frequently occur in cancer (30). The overexpression of c-Met has been detected in several types of human cancer, including liver, lung, colorectal, stomach, and colon cancer (31-35), and is usually associated with poor outcome. Consistent with these studies, the present study also found that c-Met protein was overexpressed in lung cancer tissues. Furthermore, TPST-1 was significantly negatively correlated with c-Met expression in lung cancer. In addition to the other results of the present study, this result implied that TPST-1 may be a prognostic biomarker in lung cancer.

It should be noted that the present study has several limitations. First, the sample size was limited; further studies with larger samples may provide a more accurate prediction. Second, the expression of TPST-1 was examined only by immunohistochemistry, and no molecular studies or RNA analyses of TPST-1 were conducted. Finally, without a survival analysis, it was not possible to determine whether TPST-1 was an independent predictor of survival. Further studies are required to clarify the impact of TPST-1 expression on the survival of patients with lung cancer.

In conclusion, the expression of TPST-1 in lung cancer tumor tissues was significantly reduced compared to that in matched control lung tissues. TPST-1 expression was associated with lung cancer TNM stage and lymph node metastasis. The results of the present study also showed that TPST-1 was significantly negatively correlated with c-Met expression in lung cancer, suggesting that it may be a prognostic biomarker for lung cancer.

\section{Acknowledgements}

This work was supported by the National Natural Scientific Foundation (grant no. 81472774) and the Research Programme of the Science and Technology Department of Hunan Province (grant nos. 2012FJ4076 and 2012TT2011).

\section{References}

1. Ferlay J, Shin HR, Bray F, Forman D, Mathers C and Parkin DM: Estimates of worldwide burden of cancer in 2008: Globocan 2008. Int J Cancer 127: 2893-2917, 2010.

2. Jemal A, Siegel R, Ward E, Hao Y, Xu J, Murray T and Thun MJ: Cancer statistics, 2008. CA Cancer J Clin 58: 71-96, 2008.

3. Kamangar F, Dores GM and Anderson WF: Patterns of cancer incidence, mortality and prevalence across five continents: Defining priorities to reduce cancer disparities in different geographic regions of the world. J Clin Oncol 24: 2137-2150, 2006.

4. Schiller JH, Harrington D, Belani CP, Langer C, Sandler A, Krook J, Zhu J and Johnson DH; Eastern Cooperative Oncology Group: Comparison of four chemotherapy regimens for advanced non-small-cell lung cancer. N Engl J Med 346: 92-98, 2002.

5. Scagliotti GV, De Marinis F, Rinaldi M, Crinò L, Gridelli C, Ricci S, Matano E, Boni C, Marangolo M, Failla G, et al: Phase III randomized trial comparing three platinum-based doublets in advanced non-small-cell lung cancer. J Clin Oncol 20: 4285-4291, 2002. 
6. Paik PK, Johnson ML, D'Angelo SP, Sima CS, Ang D, Dogan S, Miller VA, Ladanyi M, Kris MG and Riely GJ: Driver mutations determine survival in smokers and never-smokers with stage IIIB/IV lung adenocarcinomas. Cancer 118: 5840-5847, 2012.

7. An SJ, Chen ZH, Su J, Zhang XC, Zhong WZ, Yang JJ, Zhou Q, Yang XN, Huang L, Guan JL, et al: Identification of enriched driver gene alterations in subgroups of non-small cell lung cancer patients based on histology and smoking status. PLoS One 7: e40109, 2012.

8. Beau-Faller M, Ruppert AM, Voegeli AC, Neuville A, Meyer N, Guerin E, Legrain M, Mennecier B, Wihlm JM, Massard G, et al: MET gene copy number in non-small cell lung cancer: Molecular analysis in a targeted tyrosine kinase inhibitor naive cohort. J Thorac Oncol 3: 331-339, 2008.

9. Bearz A, Passalacqua R, Alabiso O, Cinieri S, Gridelli C, Cravesana $\mathrm{C}$ and Crinò L: First-line bevacizumab-based therapy in advanced non-squamous non-small-cell lung cancer: Analysis of the Italian patients enrolled in the SAiL study. Clin Drug Investig 32: 755-760, 2012

10. Lee RW and Huttner WB: Tyrosine-O-sulfated proteins of PC12 pheochromocytoma cells and their sulfation by a tyrosylprotein sulfotransferase. J Biol Chem 258: 11326-11334, 1983.

11. Ouyang YB and Moore KL: Molecular cloning and expression of human and mouse tyrosylprotein sulfotransferase-2 and a tyrosylprotein sulfotransferase homologue in Caenorhabditis elegans. J Biol Chem 273: 24770-24774, 1998.

12. Beisswanger R, Corbeil D, Vannier C, Thiele C, Dohrmann U, Kellner R, Ashman K, Niehrs C and Huttner WB: Existence of distinct tyrosylprotein sulfotransferase genes: Molecular characterization of tyrosylprotein sulfotransferase-2. Proc Natl Acad Sci USA 95: 11134-11139, 1998.

13. Moore KL: The biology and enzymology of protein tyrosine O-sulfation. J Biol Chem 278: 24243-24246, 2003.

14. Mishiro E, Sakakibara Y, Liu MC and Suiko M: Differential enzymatic characteristics and tissue-specific expression of human TPST-1 and TPST-2. J Biochem 140: 731-737, 2006.

15. Zhao H, Langerod A, Ji Y, Nowels KW, Nesland JM, Tibshirani R, Bukholm IK, Kåresen R, Botstein D, Børresen-Dale AL and Jeffrey SS: Different gene expression patterns in invasive lobular and ductal carcinomas of the breast. Mol Biol Cell 15: 2523-2536, 2004.

16. Toruner GA, Ulger C, Alkan M, Galante AT, Rinaggio J, Wilk R, Tian B, Soteropoulos P, Hameed MR, Schwalb MN and Dermody JJ: Association between gene expression profile and tumor invasion in oral squamous cell carcinoma. Cancer Genet Cytogenet 154: 27-35, 2004.

17. Barretina J, Taylor BS, Banerji S, Ramos AH, Lagos-Quintana M, Decarolis PL, Shah K, Socci ND, Weir BA, Ho A, et al: Subtype-specific genomic alterations define new targets for soft-tissue sarcoma therapy. Nat Genet 42: 715-721, 2010.

18. Xu J, Deng X, Tang M, Li L, Xiao L, Yang L, Zhong J, Bode AM, Dong Z, Tao Y and Cao Y: Tyrosylprotein sulfotransferase-1 and tyrosine sulfation of chemokine receptor 4 are induced by Epstein-Barr virus encoded latent membrane protein 1 and associated with the metastatic potential of human nasopharyngeal carcinoma. PLoS One 8: e56114, 2013.

19. Landi L, Minuti G, D'Incecco A and Cappuzzo F: Targeting c-MET in the battle against advanced nonsmall-cell lung cancer. Curr Opin Oncol 25: 130-136, 2013.

20. Di Renzo MF, Olivero M, Ferro S, Prat M, Bongarzone I, Pilotti S, Belfiore A, Costantino A, Vigneri R and Pierotti MA: Overexpression of the c-MET/HGF receptor gene in human thyroid carcinomas. Oncogene 7: 2549-2553, 1992.
21. Natali PG, Nicotra MR, Di Renzo MF, Prat M, Bigotti A Cavaliere R and Comoglio PM: Expression of the c-Met/HGF receptor in human melanocytic neoplasms: Demonstration of the relationship to malignant melanoma tumour progression. Br J Cancer 68: 746-750, 1993.

22. Rami-Porta R, Crowley JJ and Goldstraw P: The revised TNM staging system for lung cancer. Ann Thorac Cardiovasc Surg 15: 4-9, 2009.

23. Jiang J, Zhu Y, Wu C, Shen Y, Wei W, Chen L, Zheng X, Sun J, Lu B and Zhang X: Tumor expression of B7-H4 predicts poor survival of patients suffering from gastric cancer. Cancer Immunol Immunother 59: 1707-1714, 2010.

24. Hamamoto J, Soejima K, Yoda S, Naoki K, Nakayama S, Satomi R, Terai H, Ikemura S, Sato T, Yasuda H, et al: Identification of microRNAs differentially expressed between lung squamous cell carcinoma and lung adenocarcinoma. Mol Med Rep 8: 456-462, 2013.

25. Mishiro E, Liu MY, Sakakibara Y, Suiko M and Liu MC: Zebrafish tyrosylprotein sulfotransferase: Molecular cloning, expression and functional characterization. Biochem Cell Biol 82: 295-303, 2004.

26. Westmuckett AD, Hoffhines AJ, Borghei A and Moore KL: Early postnatal pulmonary failure and primary hypothyroidism in mice with combined TPST-1 and TPST-2 deficiency. Gen Comp Endocrinol 156: 145-153, 2008.

27. Komori R, Amano Y, Ogawa-Ohnishi M and Matsubayashi Y: Identification of tyrosylprotein sulfotransferase in Arabidopsis. Proc Natl Acad Sci USA 106: 15067-15072, 2009.

28. Sherry DM, Murray AR, Kanan Y, Arbogast KL, Hamilton RA, Fliesler SJ, Burns ME, Moore KL and Al-Ubaidi MR: Lack of protein-tyrosine sulfation disrupts photoreceptor outer segment morphogenesis, retinal function and retinal anatomy. Eur J Neurosci 32: 1461-1472, 2010.

29. Cooper CS, Park M, Blair DG, Tainsky MA, Huebner K, Croce CM and Vande Woude GF: Molecular cloning of a new transforming gene from a chemically transformed human cell line. Nature 311: 29-33, 1984.

30. Yamamoto S, Tsuda H, Miyai K, Takano M, Tamai S and Matsubara O: Gene amplification and protein overexpression of MET are common events in ovarian clear-cell adenocarcinoma: Their roles in tumor progression and prognostication of the patient. Mod Pathol 24: 1146-1155, 2011.

31. Sun YL, Liu WD, Ma GY, Gao DW, Jiang YZ, Liu Q and Du JJ. Expression of HGF and Met in human tissues of colorectal cancers: Biological and clinical implications for synchronous liver metastasis. Int J Med Sci 10: 548-559, 2013.

32. Siemens H, Neumann J, Jackstadt R, Mansmann U, Horst D, Kirchner T and Hermeking H: Detection of miR-34a promoter methylation in combination with elevated expression of c-Met and $\beta$-catenin predicts distant metastasis of colon cancer. Clin Cancer Res 19: 710-720, 2013.

33. Patil MA, Lee SA, Macias E, Lam ET, Xu C, Jones KD, Ho C, Rodriguez-Puebla $\mathrm{M}$ and Chen X: Role of cyclin D1 as a mediator of c-Met-and beta-catenin-induced hepatocarcinogenesis. Cancer Res 69: 253-261, 2009

34. Jardim D L, de Melo Gagliato D, Falchook GS, Janku F, Zinner R, Wheler JJ, Subbiah V, Piha-Paul SA, Fu S, Murphy MB, et al: MET aberrations and c-MET inhibitors in patients with gastric and esophageal cancers in a phase I unit. Oncotarget 5: 1837$1845,2014$.

35. Sun W, Ai T, Gao Y, Zhang Y, Cui J and Song L: Expression and prognostic relevance of MET and phospho-BAD in non-small cell lung cancer. Onco Targets Ther 6: 1315-1323, 2013. 